\title{
VERBOS TERMINADOS EN -IFICAR DESDE UNA PERSPECTIVA DIACRÓNICA: UN ANÁLISIS PRELIMINAR DE CORPUS*
}

\author{
ZUZANA KRINKOVÁ \\ Universidad Carolina, Praga
}

\section{VERBS ENDING IN -IFICAR FROM A DIACHRONIC PERSPECTIVE: A PRELIMINARY CORPUS-BASED ANALYSIS}

The article deals with the incorporation of verbs ending in -ificar into Spanish from a historical perspective. Our analysis is based on the Spanish corpus CORDE and covers the period between the 13th and the first half of the 20th centuries. The qualitative part of the analysis takes for its objective to observe the nominal or adjectival character of the bases used in the verbs ending in -ificar and, further, their Latin or Spanish origin. At the same time, we observe in each 50-year time period (starting in 1200 and ending in 1950) their type frequency, i.e. how the number of verbs varies, which verbs newly appear in the Spanish lexicon and which ones, on the contrary, disappear from usage. In the quantitative analysis, we compare the token frequency of these forms (and their derivates) in each 50 -year time period.

Keywords: suffix; ificar; CORDE; corpus linguistics; diachrony; loan verbs

Palabras clave: sufijo; ificar; CORDE; lingüística de corpus; diacronía; préstamos verbales

\section{Introducción}

En general se puede constatar que la abrumadora mayoría de los verbos que terminan en el sufijo -ificar han ido incorporándose en el español durante la historia como préstamos. En los tiempos medievales se trataba de préstamos cultos tomados directamente del latín que sobre todo debían llenar lagunas en el léxico de la lengua castellana. Más tarde, con la creciente influencia cultural de algunas lenguas europeas, estos verbos (junto con muchos otros latinismos) empezaron a penetrar en el español a través del ita-

* Este artículo forma parte del proyecto "Program rozvoje vědních oblastí na Univerzitě Karlově č. P10", subprograma "Románské jazyky ve světle jazykových korpusư”. 
liano, francés ${ }^{1}$ e inglés ${ }^{2}$. Este artículo se ocupa de la incorporación de tales verbos (y sus derivados) desde una perspectiva diacrónica y presenta una investigación preliminar de corpus que, dada la extensión del artículo, no puede tratar sobre el tema de una manera exhaustiva. Creemos, sin embargo, que nuestro artículo puede servir bien como punto de partida para otros estudios que se ocupen del sufijo -ificar en el campo de la neología o productividad, $y$, también, p. ej. en los estudios contrastivos, tanto entre las lenguas en las que existe este sufijo (p. ej. -ificare en italiano, -ify en inglés, -ifier en francés), como en los estudios en los que se compare el uso de este sufijo con otro de significado parecido (p. ej. -ificar frente a -izar, sufijo de significado y función parecidas).

En el artículo se van a presentar los resultados del análisis de corpus que cubre el periodo temporal desde el siglo XIII hasta la primera mitad del siglo XX. La investigación puede ser dividida en dos partes: la parte cualitativa y la cuantitativa.

La parte cualitativa toma por objetivo la verificación de las afirmaciones hechas sobre del carácter nominal o adjetival de las bases usadas para derivar los verbos terminados en -ificar y, también, sobre el origen culto (latín) o popular (castellano) de dichas bases. A la vez se observa cómo cambia el número ${ }^{3}$ total de los verbos en -ificar empleados en el corpus de los textos en cada periodo de 50 años (empezando en 1200 y terminando en 1950), cuáles verbos aparecen en los textos por primera vez y cuáles, por el contrario, desaparecen.

La parte cuantitativa se centra en la frecuencia relativa de los tokens ${ }^{4}$ de los verbos terminados en -ificar y sus derivados en cada periodo de 50 años. Observamos cómo la frecuencia de tales verbos en el texto tiende a subir o bajar, $y$, donde sea posible intentamos proponer posibles razones por las cuales pueda suceder así.

\section{Sufijos de origen latín y griego presentes en el español}

El latín y el griego disponen de una amplia escala de prefijos y sufijos, y el español ha incorporado durante su historia muchos vocablos que contienen estos sufijos. Mientras que los prefijos en las palabras cultas han permanecido sin cambio (p. ej. los prefijos des-, infra-, sub-, etc.), los sufijos a veces han sufrido una ligera adaptación al sistema fonológico español ${ }^{5}$.

Pharies (2004: 157) cita los siguientes ejemplos de sufijos cultos de origen latino: -áceo (grisáceo), -ancia (colindancia), -áneo (cutáneo), -ario (disciplinario), -átil (por-

1 De hecho, el contacto con el francés y el provenzal se da ya en el siglo XI y continúa a lo largo del Medioevo, debido a la presencia de las órdenes de Cluny y del Císter, la participación de militares franceses en las campañas de la Reconquista, o el impacto de la épica francesa y la poesía trovadoresca provenzal.

2 De hecho, a partir del siglo XVII ya no se puede hablar de palabras cultas o latinismos, sino más bien de internacionalismos, porque estas palabras se encuentran en varios idiomas, incluso en los no románicos.

3 Es decir, se trata aquí de la type frequency, cf. p. ej. Bauer (2001: 47).

4 En el corpus (que es un conjunto de textos), una palabra (lema) suele ocurrir más veces, o sea, suele tener más tokens.

5 Cf. los procesos de adaptación mencionados por Alvar - Mariner (1967: 12-14). 
tátil), -ción (acentuación), -encia (mantenencia), -ense (bonaerense), -íneo (jazmíneo), -iva (negativa), -ivo (deportivo), -menta (ornamenta), -or (temblor), -(i)ficar (petrificar). Los sufijos de origen griego han penetrado en el español a través del latín: -aico (prosaico), -ático (maniático), -iaco (policiaco), -isa (sacerdotisa), -ístico (automovilístico), -ita (israelita), -oide (sufijoide), -teca (filmoteca), -izar (fertilizar).

Muchos de los sufijos cultos tienen a la vez también sus homólogos populares del mismo origen etimológico, que han sufrido el cambio fonológico regular, como, por ejemplo, el sufijo popular - ero (atracadero) y el culto -orio (lavatorio), ambos del lat. -ŌRIU; el sufijo popular -miento (llamamiento) y el culto -mento (pulimento), del lat. -MENTU.

Los sufijos verbales -ear e -izar provienen originalmente del sufijo griego causativo

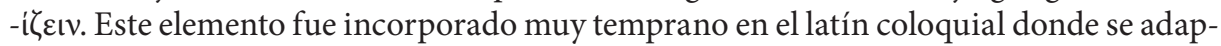
tó como -IDIĀRE y con el cambio regular fonológico adquirió la forma-ear que aparece en español. El latín literario tardío incorporó más tarde el sufijo griego -ił̌cıv de nuevo, esta vez en la forma -IZĀRE, y éste más tarde aparece en el español medieval en los préstamos cultos como -izar. Este sufijo es muy productivo en el español moderno. Como menciona Lavale Ortiz (2007: 15-16), se añade a bases nominales y adjetivales (con prevalencia de las segundas) y expresa primordialmente causatividad o cambio de estado. Algunos de los sufijos cultos empezaron a ser productivos en el español y comenzaron a unirse también con voces populares. Penny (2001: 262) cita como ejemplo los siguientes sufijos: -ía ${ }^{6}$,-ismo, -ista, -ante, -(i)ente, -ancia, -(i)encia, -orio, -mento, -ción. A la vez añade que algunos de los sufijos cultos son más productivos en el español actual que sus homólogos populares del mismo origen etimológico, por ejemplo el sufijo culto -ancia (frente al sufijo popular -anza, ambos provienen del sufijo lat. -ANTIA), -ción (frente al popular -zón, ambos del lat. -TIŌNE).

Pharies (2004: 157) dice que algunos de los sufijos cultos sufrieron una modificación de significado o función: p. ej. el sufijo -ía (de origen griego) fue originalmente un sufijo nomina qualitatis, más tarde su significado se extendió también a denominaciones de talleres, tiendas u oficinas (escribanía, alcaldía, librería) y colectivos (burguesía); el sufijo grecolatino -ista, que originalmente se aplicó a bases verbales, en español se une comúnmente con bases nominales (droga $>$ droguista).

La problemática de la incorporación de los sufijos cultos latinos y griegos en el español (incluida su competencia con sus eventuales homólogos de origen popular) no ha sido estudiada detalladamente hasta hoy, faltan sobre todo estudios desde la perspectiva diacrónica.

\section{El sufijo-ificar}

Igualmente como en el caso del arriba mencionado sufijo verbal -izar, la historia del sufijo -ificar es relativamente compleja. Gómez de Silva (1998: 365) deriva su origen del sufijo latín (tardío) -(I)FICĀRE, que es una terminación verbal derivada de -FICUS?.

6 Por ejemplo, alegría, cobardía, alcaldía.

7 Cf. el sufijo adjetival -(i)fico: científico, magnífico, pacífico, etc. 
Ésta tiene su origen en el verbo latino FACERE. Como menciona Penny (2001: 264), el sufijo culto -ificar también tiene su homólogo popular, el sufijo -iguar.

Igualmente como el sufijo -izar, también el sufijo -ificar tiene primordialmente función causativa y puede unirse con bases nominales y adjetivales ${ }^{8}$. A diferencia del sufijo -izar prevalecen con él, según Lavale Ortiz (2007), las bases nominales (p. ej. calcificar, gasificar, petrificar). La mayoría de los verbos derivados de las bases nominales pertenece al campo léxico de la ciencia y la tecnología. Rifón (1997: 119) cita que los tecnicismos formados de esta manera suelen tener un significado no factitivo y a menudo tienen sus homólogos verbales con un sufijo más productivo, como ocurre, por ejemplo, en la pareja damnificar y dañar.

Según apunta Lavale Ortiz (2007), los verbos en -ificar derivados de bases adjetivales son menos frecuentes, pero pertenecen al vocabulario común (p. ej. identificar, simplificar).

\section{Descripción del corpus y de la metodología}

Para nuestro análisis de corpus hemos usado el corpus diacrónico de la Real Academia Española llamado CORDE 9 . Se trata del corpus diacrónico más extenso de la lengua española (con un número total de 250.000 .000 palabras). El corpus contiene textos de diferentes géneros y lugares (España, Hispanoamérica...) que se datan en el periodo que se extiende desde los comienzos de la lengua española ${ }^{10}$ hasta 1975. Durante la búsqueda, si es necesario, los textos pueden ser filtrados según género, lugar o fecha de su origen.

El corpus CORDE tiene, sin embargo, varias desventajas que dificultan el trabajo con él. Hemos tenido que tomar en consideración sobre todo las siguientes:

1) La proporción de los textos en cuanto a su datación está distribuida aproximadamente de la siguiente manera: hasta 1492: el 21\%, 1493-1713: el 28\% y 1714-1975: el 51\%. Esta información es, sin embargo, insuficiente si queremos comparar la ocurrencia de un fenómeno en un periodo de tiempo diferente. Por eso hemos tenido que recurrir a un método auxiliar (véase más adelante) para poder distinguir la proporción del tamaño del corpus en cada siglo.

2) El corpus no está lematizado. Permite buscar partes de palabras (p. ej. sufijos) mediante el comodín *, pero sin otra distinción (p. ej. partes de la oración). El trabajo resulta particularmente complicado si se lleva a cabo una búsqueda de verbos por las numerosas formas de su conjugación en varios tiempos y modos. Por esta razón, en la primera fase, la búsqueda se ha limitado solo a las formas verbales terminadas en -ificar ${ }^{11} \mathrm{y}$, al final, ha sido necesario incluir en el análisis también los derivados

8 Cf. Lavale Ortiz (2007: 16).

9 Online accesible en: http://corpus.rae.es/cordenet.html

10 Los textos más antiguos del CORDE que están escritos en iberorromance provienen del principio del siglo IX. Se trata de documentos notariales y ordenamientos legales.

$11 \mathrm{O}$ sea en infinitivo. Otras formas, como p. ej. ${ }^{\star} i f i c a^{\star}$ o incluso ${ }^{\star} i f i c^{\star}$ han sido imposibles, ya que el corpus es capaz de procesar solamente hasta un cierto número de palabras y si se supera ese número, el sistema indica error. 
de los verbos terminados en -ificar (p. ej. cualificar $\rightarrow$ cualificación). Sin embargo, del análisis han sido excluidas las formas nominales que no se derivan de dichos verbos, aunque estén relacionadas etimológicamente con ellos (p. ej. pontífice y pontificar u orifice y orificar), y las formas que tienen un origen etimológico diferente, p. ej. orificio, del lat. ORIFICIUM, frente a orificar - del esp. oro + sufijo -ificar).

3) El corpus contiene también textos escritos en latín que se datan sobre todo en el periodo más antiguo. No es posible filtrar los textos según el idioma en el que están escritos. Este hecho complica bastante la investigación de los préstamos que vienen del latín porque la misma forma (o forma muy similar) puede aparecer tanto en un texto español como en un texto latino. Por eso es necesario hacer un control de la lengua de cada texto donde aparece dicha palabra.

La búsqueda en el corpus ha consistido de dos pasos:

1) En cada periodo de 50 años hemos introducido en el formulario de consulta la forma *ificar para obtener la lista de infinitivos que contienen este sufijo. Hemos empezado en 1200 y, repitiendo esta consulta en cada siglo, más y más verbos fueron añadiéndose a la lista. En este primer paso no fue posible consultar una forma más general como ${ }^{\star} i f i c^{\star}$ o ${ }^{\star} i f i c a^{\star}$ porque eso generaría demasiados tokens encontrados y haría imposible obtener los ejemplos concretos de los verbos en cuestión.

2) La búsqueda ha sido repetida para cada verbo introduciendo dos consultas más generales (p. ej. para el verbo clasificar, hemos introducido clasific $^{\star}$ y clasifiq $^{*}$ ) en cada periodo de tiempo (desde 1200 hasta 1950). De este modo hemos adquirido todas las formas verbales y sus derivados. En caso de existencia de una palabra que no sea un derivado del verbo terminado en -ificar (como orificio), tales formas han sido sustraídas (p. ej. en este caso concreto hemos excluido todas las formas en orifici* y orifice ${ }^{\star}$ en cada periodo de tiempo).

\section{Resultados del análisis cualitativo}

En el corpus de la primera mitad del siglo XIII se registran 17 verbos en -ificar ${ }^{12}$. Todas las formas están documentadas en el latín tardío ${ }^{13}$ y las bases (tanto nominales cuanto adjetivales en relación $10: 7$ ) copian las formas latinas, aunque hay algunas variantes ortográficas (como certificar/çertificar, edificar/hedificar) y en algunos casos aparece una reducción en el grupo consonántico (santificar al lado de sanctificar, sinificar al lado de significar). En la segunda mitad del siglo XIII se puede observar el crecimiento de tokens de los verbos previamente documentados y se registran 10 nuevos verbos $^{14}$ (sus bases nominales y adjetivales están en relación $3: 7$ ). Por lo demás las

12 La lista contiene los verbos siguientes: certificar, crucificar, edificar, fructificar, glorificar, honorificar, magnificar, mortificar, notificar, pacificar, purificar, ratificar, sacrificar, sanctificar, significar, versificar, vivificar.

13 Con una excepción probable de ratificar, según el Diccionario de la Real Academia (DRAE), que menciona el origen del lat. RATUS y el sufijo -ficar.

14 Esos son: clarificar, danificar, diversificar, fortificar, gratificar, justificar, mundificar, pontificar, rectificar, verificar. 
tendencias son similares a las del periodo precedente. Otra vez, las variantes ortográficas (p. ej. iustificar/justificar, pacificar/paçificar, significar/sygnificar, verificar/uerificar) y reducciones de grupos consonánticos (danificar < lat. DAMNIFICĀRE, retificar/rectificar < lat. RECTIFICĀRE) aparecen esporádicamente. Todos los verbos nuevos se documentan en el latín tardío también.

En la primera mitad del s. XIV se pueden ver algunos cambios en comparación con el periodo anterior. El crecimiento de tokens no puede ser considerado general, algunos verbos del periodo precedente no aparecen ${ }^{15}$ y se documentan solo 4 nuevos verbos ${ }^{16}$ (sus bases nominales prevalecen en relación $3: 1$, solo dos de los verbos se documentan en el latín tardío según el DRAE, pero todas las bases son latinas, o sea cultas).

La segunda mitad del s. XIV está caracterizada por el renacimiento del sufijo -ificar: el crecimiento de los tokens de los verbos documentados previamente (así como el crecimiento de sus variantes ortográficas, p. ej. damnificar/dampnificar/dannificar/ dapnificar) es considerable, 8 verbos aparecen por primera vez ${ }^{17}$ (con 3 bases nominales frente a 5 adjetivales, todas son latinas y cultas), se documentan algunas formas con $a$ - protética $^{18}$.

La tendencia del crecimiento general sigue durante todo el siglo XV. Hay siempre numerosas variantes ortográficas ${ }^{19} \mathrm{y}$ algunas formas con $a$-protética. Algunos verbos documentados esporádicamente por primera vez en este siglo desaparecen más tarde de la lengua (p. ej. aptificar, minorificar, estrellificar, frantificar) o reaparecen mucho más tarde (p. ej. dulcificar, vitrificar). En la primera mitad del siglo XV se registran dieciocho verbos nuevos y en la segunda, ocho ${ }^{20}$. Sin embargo, a partir del siglo XV ya no es oportuno generalizar los verbos nuevos en -ificar como latinismos o cultismos, ya que, en muchos casos, penetraron en el idioma español a través de otra lengua europea.

La variabilidad de formas continúa durante todo el siglo XVI, pero las formas con $a$ - protética desaparecen. No se documentan verbos nuevos en la primera mitad del siglo XVI, mientras que en la segunda mitad solo dos verbos ${ }^{21}$ se registran por primera vez. Para todo el siglo es característico un crecimiento significativo en el uso de algunos verbos previamente documentados 22 .

15 Los verbos diversificar, fortificar, mortificar, mundificar no se documentan en este periodo.

16 Esos son: especificar (según DRAE, derivado del adjetivo específico (< lat. tardío SPECIFĪCUS), metrificar (< lat. METRUM y -ficar), modificar (< lat. MODIFICĀRE) y testificar ( $<$ lat. TESTIFICĀRI).

17 Esos son: amplificar (< lat. AMPLIFICĀRE), beatificar (< lat. BEATIFICĀRE), deificar ( $<$ lat. DEIFICĀRE), diversificar (< lat. DIVERSIFICĀRE), exemplificar (<lat. EXEMPLUM y -ficar), falsificar (<lat. FALSIFICĀRE), molificar/mollificar (< lat. MOLLIFICĀRE), odorificar (< lat. ODOR y -ficar).

18 Esas son: amollificar, amortificar, asacrificar, apacificar - esta forma está, sin embargo, documentada ya en la primera mitad de ese siglo.

19 P. ej. dagnificar, damnificar, dampnificar, danificar, dañificar, dannificar, dapnificar, dapñificar ( $<$ lat. DAMNIFICĀRE).

20 Esos son: calificar (< lat. QUALIFICĀRE), clasificar (< lat. CLASSIFICĀRE), escarnificar?, esclarificar? (< lat. CLARIFICĀRE?), esdificar (<?), lubrificar (< lat. LUBRİCUS e -ificar), panificar (< lat. PANIS y -ficar), restificar (< lat. ?)

21 El primero es identificar (según DRAE, del esp. idéntico, con la supresión de la última sílaba e -ificar), el segundo es nidificar ( $<$ lat. NIDIFICĀRE).

22 Especialmente los verbos certificar, edificar, fortificar, justificar, notificar, sacrificar, significar son muy frecuentes. 
Algunas tendencias similares (un reducido número de verbos ${ }^{23}$, crecimiento de la frecuencia de uso de algunos verbos) siguen también durante los siglos XVII y XVIII. La variabilidad de formas ortográficas ${ }^{24} \mathrm{y}$ fonéticas está siempre presente, aunque en la segunda mitad del siglo XVII disminuye un poco. En el siglo XVIII se puede advertir una relativa estabilización de formas ortográficas en favor del estado actual ${ }^{25}$, o sea de las variantes se imponen ya las formas que conocemos hoy en día ${ }^{26}$. El cuadro completo de todos los verbos y sus ocurrencias en varios periodos se puede ver en la Tabla 2 (al final del apartado 5).

\section{Resultados del análisis cuantitativo}

Primeramente, nos limitaremos a cuantificar las ocurrencias de los verbos acabados en -ificar y sus derivados que hemos hallado en el CORDE en los determinados periodos de tiempo. Como se puede ver en la Figura 1, el número de tales ocurrencias cambia considerablemente durante el tiempo. Los valores máximos parecen ser alcanzados en el periodo de 1551 a 1600 y, después, en el siglo XX, mientras que valores relativamente bajos se pueden ver hasta 1450 y, también, el periodo entre 1651 y 1850 parece ser relativamente pobre en la incidencia de este sufijo. Esta deducción es, sin embargo, engañosa e inadecuada porque no refleja el tamaño del corpus de cada periodo.

-ificar

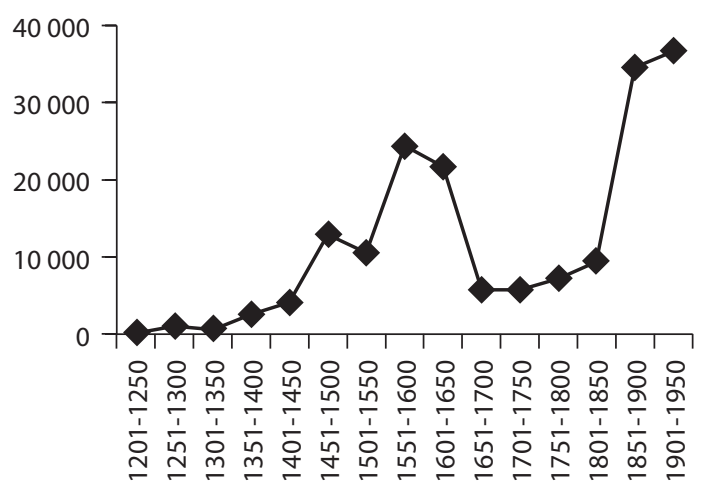

Figura 1. Número de tokens en -ific-/-ifiq- (valores absolutos)

23 Solo tres verbos nuevos se documentan en el siglo XVII: intensificar (del lat. INTENSUS/esp. intenso e -ificar), orificar (del esp. oro e -ificar) y polvificar (del esp. polvo e -ificar).

24 En la primera (pero no en la segunda) mitad del siglo XVII se documentan formas escritas con $k$ : -ikar (p. ej. sinifikar).

25 Hecho sin duda relacionado con la fundación de la RAE.

26 En la segunda mitad del s. XIX aparecen solo tres verbos nuevos (solidificar, mistificar, momificar), mientras que en la primera mitad del siglo XX, diez (descalificar, dosificar, cuantificar, henificar, acidificar, desmitificar, escenificar, estratificar, gasificar, ramificar). 
De hecho, la parte cuantitativa de nuestro análisis de corpus requiere una determinación más específica del volumen total del corpus de textos en cada periodo de 50 años. Para obtener tal información hemos recurrido a un método auxiliar. Hemos elegido como punto de referencia el artículo determinado el, cuya ocurrencia hemos relacionado a cada periodo de 50 años (hemos cubierto el periodo desde 1100 hasta 1975)27. Hemos comparado los resultados obtenidos de esta manera con la información dada en la página web del CORDE y la desviación no ha sido muy significativa: un $16 \%$ hasta 1492 (frente a un 21\%), un 34\% entre 1493-1713 (frente a un 28\%) y un 50\% entre 1714 y 1975 (frente a un 51\%) ${ }^{28}$.

Tabla 1. Número de tokens en -ific-/-ifiq-

\begin{tabular}{|c|c|c|c|}
\hline periodo de tiempo & $\begin{array}{c}\text { Cúmero de tokens en } \\
\text {-ific-/-ifiq- }\end{array}$ & $\begin{array}{c}\text { CORDE - } \\
\text { estimación del } \\
\text { número total de } \\
\text { tokens }\end{array}$ & \%ificar \\
\hline $1201-1250$ & 134 & 666.986 & $0,020 \%$ \\
\hline $1251-1300$ & 1.050 & 3.725 .443 & $0,028 \%$ \\
\hline $1301-1350$ & 587 & 1.838 .567 & $0,032 \%$ \\
\hline $1351-1400$ & 2.604 & 3.140 .305 & $0,083 \%$ \\
\hline $1401-1450$ & 4.116 & 3.103 .378 & $0,133 \%$ \\
\hline $1451-1500$ & 12.934 & 7.364 .152 & $0,176 \%$ \\
\hline $1501-1550$ & 10.593 & 8.743 .783 & $0,121 \%$ \\
\hline $1551-1600$ & 24.382 & 16.301 .867 & $0,150 \%$ \\
\hline $1601-1650$ & 21.675 & 14.290 .656 & $0,152 \%$ \\
\hline $1651-1700$ & 5.764 & 3.381 .024 & $0,170 \%$ \\
\hline $1701-1750$ & 5.783 & 3.564 .790 & $0,162 \%$ \\
\hline $1751-1800$ & 7.225 & 4.206 .644 & $0,172 \%$ \\
\hline $1801-1850$ & 9.330 & 5.911 .015 & $0,158 \%$ \\
\hline $1851-1900$ & 34.532 & 16.864 .850 & $0,205 \%$ \\
\hline $1901-1950$ & 36.634 & 18.445 .602 & $0,199 \%$ \\
\hline & & & \\
\hline & & & \\
\hline
\end{tabular}

27 Somos conscientes de que los resultados obtenidos así pueden ser distorsionados hasta cierto punto, sobre todo en los periodos tempranos, porque aunque los artículos definidos aparecen ya en las fuentes españolas más antiguas, su uso no se consolidó hasta el siglo XV. Además, con este método, los textos en latín están excluidos, lo que, sin embargo, sirve bien para nuestro análisis de verbos (que en su mayor parte son latinismos).

28 Creemos que la desviación obtenida se debe sobre todo a la ausencia de los textos en latín que están incluidos en mayor medida precisamente en el primer periodo. 
Hemos relacionado el número de tokens en -ific-lifiq- en cada periodo a la estimación del número total de palabras (tokens) presentes en el CORDE en los periodos correspondientes (véase Tabla 1).

Como se puede ver en la Figura 2, las ocurrencias de verbos en -ificar y sus derivados relacionados al tamaño de corpus de cada periodo muestra una curva diferente. Podemos observar un crecimiento sustancial que se inicia en el periodo de 1351-140029 y alcanza su máximo en 1451-1500. Una caída considerable se nota en la primera mitad del siglo XVI ${ }^{30}$. Sigue un periodo relativamente estable de ocurrencia más alta que se data entre 1551 y 1850 . En la segunda mitad del siglo XIX aparece nuevamente otro crecimiento considerable de las ocurrencias. Una caída interesante se advierte en el siglo $\mathrm{XX}^{31}$. La significación estadística del crecimiento o caída en nuestro análisis fue probada por el likelihood ratio test ${ }^{32}$.

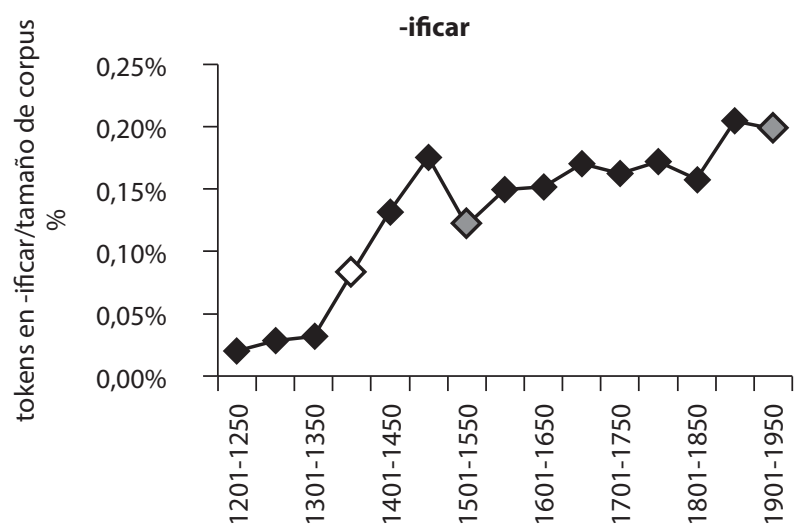

Figura 2. Número de tokens en -ific-/-ifiq-

(valores relacionados al número total de tokens estimado para cada periodo)

29 Este crecimiento es significativo desde el punto de vista estadístico, con el p-valor 2,20E-16, según el likelihood ratio test.

30 Esta caída es significativa desde el punto de vista estadístico, con el p-valor 2,20E-16.

31 También esta caída es significativa, con el p-valor 4,69E-05.

32 Cf. Dunning 2004. 
Tabla 2. Verbos en -ific-/-ifiq-en varios periodos (según CORDE) $)^{33}$

\begin{tabular}{|c|c|c|c|c|c|c|c|c|c|c|c|c|c|c|c|c|c|}
\hline $\begin{array}{l}\stackrel{0}{\circ} \\
\stackrel{0}{\circ}\end{array}$ & 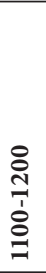 & 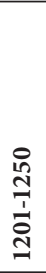 & 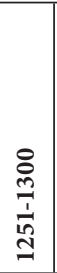 & 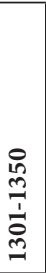 & \begin{tabular}{l}
8 \\
\multirow{+}{1}{} \\
$\frac{1}{n}$ \\
0 \\
-1
\end{tabular} & 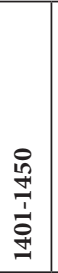 & $\begin{array}{l}8 \\
8 \\
17 \\
1 \\
15 \\
-1\end{array}$ & $\begin{array}{l}0 \\
0 \\
10 \\
1 \\
0 \\
0 \\
0\end{array}$ & $\begin{array}{c}8 \\
0 \\
1 \\
1 \\
10 \\
10 \\
-1\end{array}$ & $\begin{array}{l}0 \\
10 \\
0 \\
1 \\
1 \\
0 \\
0 \\
-1\end{array}$ & $\begin{array}{l}8 \\
1 \\
\frac{1}{10} \\
0 \\
-1\end{array}$ & 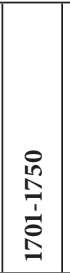 & 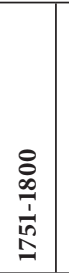 & $\begin{array}{l}0 \\
1 \\
\infty \\
1 \\
0 \\
0 \\
\infty\end{array}$ & $\begin{array}{l}8 \\
\stackrel{8}{2} \\
\frac{1}{10} \\
\infty \\
\end{array}$ & 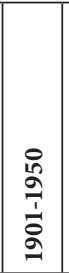 & 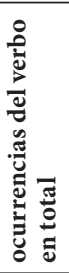 \\
\hline significar & 0 & 1 & 10 & 5 & 13 & 139 & 146 & \begin{tabular}{l|l}
183 & 6 \\
\end{tabular} & 685 & 476 & 95 & 112 & 94 & 134 & 242 & 415 & 2.750 \\
\hline edificar & 0 & 0 & 9 & 4 & 32 & 15 & 153 & \begin{tabular}{l|l}
304 & 4 \\
\end{tabular} & 475 & 356 & 84 & 50 & 66 & 84 & 191 & 270 & 2.093 \\
\hline sacrificar & 8 & 4 & 81 & 5 & 81 & 26 & 116 & \begin{tabular}{l|l}
290 & 3 \\
\end{tabular} & 349 & 178 & 47 & 61 & 90 & \begin{tabular}{l|l}
153 \\
\end{tabular} & 303 & 234 & 2.026 \\
\hline justificar & 1 & 0 & 0 & 0 & 7 & 12 & 27 & \begin{tabular}{l|l}
68 & 1 \\
\end{tabular} & 135 & 149 & 21 & 58 & 57 & 128 & 477 & \begin{tabular}{|l|}
476 \\
\end{tabular} & 1.616 \\
\hline $\begin{array}{l}\text { verificar / } \\
\text { uerificar }\end{array}$ & 0 & 0 & 5 & 0 & 1 & 8 & 14 & 191 & 119 & 77 & 30 & 41 & 108 & 157 & 338 & 268 & 1.185 \\
\hline notificar & 0 & 0 & 0 & 0 & 37 & 41 & 246 & \begin{tabular}{l|l}
238 & 1 \\
\end{tabular} & 187 & 81 & 21 & 9 & 13 & 10 & 65 & 27 & 975 \\
\hline calificar & 0 & 0 & 0 & 0 & 0 & 0 & 0 & 0 & 16 & 100 & 23 & 31 & 29 & 121 & 299 & 227 & 846 \\
\hline fortificar & 0 & 0 & 0 & 0 & 15 & 10 & 52 & \begin{tabular}{l|l}
47 & 1 \\
\end{tabular} & 156 & 235 & 28 & 55 & 37 & 34 & 110 & 43 & 822 \\
\hline $\begin{array}{l}\text { pacificar / } \\
\text { paçificar }\end{array}$ & 0 & 0 & 0 & 0 & 30 & 11 & 86 & 1462 & 232 & 106 & 29 & 14 & 22 & 17 & 67 & 35 & 795 \\
\hline modificar & 0 & 0 & 0 & 0 & 0 & 5 & 7 & 0 & 3 & 4 & 0 & 8 & 9 & 43 & 316 & \begin{tabular}{|l|}
330 \\
\end{tabular} & 725 \\
\hline rectificar & 0 & 0 & 205 & 0 & 0 & 0 & 8 & 7 & 3 & 0 & 1 & 8 & 19 & 50 & 191 & 209 & 701 \\
\hline purificar & 0 & 0 & 0 & 0 & 4 & 15 & 22 & 15 & 74 & 31 & 35 & 14 & 27 & 24 & 92 & 70 & 423 \\
\hline $\begin{array}{l}\text { certificar / } \\
\text { çertificar }\end{array}$ & 0 & 0 & 4 & 5 & 8 & 19 & 47 & 75 & 99 & 51 & 3 & 5 & 13 & 11 & 34 & 28 & 402 \\
\hline mortificar & 0 & 0 & 0 & 0 & 6 & 2 & 14 & 13 & 92 & 85 & 17 & 12 & 10 & 19 & 87 & 31 & 388 \\
\hline clasificar & 0 & 0 & 0 & 0 & 0 & 0 & 4 & 0 & 4 & 0 & 0 & 0 & 2 & 11 & 125 & 169 & 315 \\
\hline hedificar & 0 & 1 & 8 & 3 & 68 & 33 & 89 & 63 & 24 & \begin{tabular}{l|l}
0 \\
\end{tabular} & 0 & 0 & 0 & 0 & 0 & \begin{tabular}{l|l}
0 \\
\end{tabular} & 289 \\
\hline reedificar & 0 & 0 & 0 & 0 & 2 & 0 & 3 & 29 & 55 & 73 & 14 & 23 & 17 & 22 & 39 & 11 & 288 \\
\hline gratificar & 0 & 0 & 1 & 1 & 1 & 4 & 32 & 64 & 74 & 37 & 4 & 16 & 17 & 1 & 10 & 12 & 274 \\
\hline santificar & 0 & 1 & 0 & 3 & 26 & 10 & 14 & 7 & 49 & 24 & 13 & 2 & 9 & 15 & 44 & 52 & 269 \\
\hline fructificar & 0 & 0 & 0 & 0 & 0 & 3 & 12 & 21 & 60 & 13 & 10 & 13 & 35 & 8 & 32 & 46 & 253 \\
\hline ratificar & 0 & 0 & 0 & 0 & 2 & 3 & 16 & 35 & 28 & 27 & 5 & 4 & 19 & 19 & 52 & 34 & 244 \\
\hline testificar & 0 & 0 & 0 & 0 & 1 & 9 & 8 & 46 & 53 & 35 & 2 & 12 & 10 & 1 & 20 & 25 & 222 \\
\hline $\begin{array}{l}\text { crucificar / } \\
\text { cruçificar }\end{array}$ & 0 & 0 & 5 & 1 & 5 & 4 & 26 & 39 & 35 & 40 & 12 & 4 & 1 & 2 & 9 & 30 & 213 \\
\hline identificar & 0 & 0 & 0 & 0 & 0 & 0 & 0 & 0 & 4 & 0 & 0 & 2 & 0 & 19 & 41 & 139 & 205 \\
\hline $\begin{array}{l}\text { especificar / } \\
\text { espeçificar }\end{array}$ & 0 & 0 & 0 & 0 & 0 & 4 & 8 & 16 & 28 & 26 & 6 & 16 & 13 & 11 & 35 & 40 & 203 \\
\hline glorificar & 0 & 1 & 3 & 0 & 13 & 7 & 7 & 12 & 50 & 11 & 4 & 1 & 3 & 3 & 28 & 46 & 189 \\
\hline mundificar & 0 & 0 & 0 & 0 & 7 & 26 & 84 & 14 & 18 & 1 & 2 & 7 & 7 & 9 & 0 & 1 & 176 \\
\hline sinificar & 0 & 0 & 0 & 1 & 1 & 3 & 3 & 35 & 53 & 70 & 0 & 0 & 0 & 0 & 0 & 0 & 166 \\
\hline simplificar & 0 & 0 & 0 & 0 & 0 & 0 & 0 & 0 & 0 & 0 & 0 & 0 & 6 & 22 & 60 & 75 & 163 \\
\hline $\begin{array}{l}\text { versificar / } \\
\text { uersificar }\end{array}$ & 0 & 3 & 16 & 1 & 0 & 5 & 2 & 0 & 3 & 7 & 2 & 13 & 7 & 19 & 21 & 23 & 122 \\
\hline clarificar & 0 & 0 & 0 & 1 & 0 & 4 & 22 & 7 & 11 & 5 & 0 & 2 & 1 & 13 & 7 & 38 & 111 \\
\hline falsificar & 0 & 0 & 0 & 0 & 0 & 1 & 1 & 0 & 4 & 3 & 1 & 2 & 4 & 4 & 36 & 32 & 88 \\
\hline
\end{tabular}

${ }^{33}$ Los verbos en la tabla están ordenados según su ocurrencia total en el corpus. Se juntan tales variantes ortográficas de un verbo en las que es cierta la pronunciación idéntica. 


\begin{tabular}{|c|c|c|c|c|c|c|c|c|c|c|c|c|c|c|c|c|c|}
\hline 䓪 & 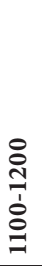 & 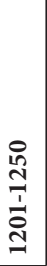 & $\begin{array}{l}8 \\
\stackrel{0}{7} \\
\frac{1}{1} \\
\\
1\end{array}$ & 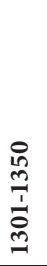 & $\begin{array}{l}8 \\
0 \\
\frac{1}{1} \\
0 \\
0 \\
0\end{array}$ & 足 & $\begin{array}{l}8 \\
0 \\
10 \\
\frac{1}{10} \\
\frac{1}{1}\end{array}$ & $\begin{array}{l}0 \\
10 \\
10 \\
1 \\
1 \\
0 \\
10 \\
10\end{array}$ & $\begin{array}{l}8 \\
0 \\
0 \\
1 \\
10 \\
10 \\
10\end{array}$ & $\begin{array}{l}0 \\
10 \\
0 \\
1 \\
1 \\
0 \\
0 \\
1\end{array}$ & $\begin{array}{l}8 \\
\frac{8}{1} \\
\frac{1}{n} \\
\frac{1}{1}\end{array}$ & $\begin{array}{l}0 \\
\stackrel{1}{1} \\
\frac{1}{2} \\
\end{array}$ & $\begin{array}{l}8 \\
0 \\
\frac{1}{11} \\
\frac{1}{2}\end{array}$ & $\begin{array}{l}0 \\
10 \\
0 \\
1 \\
0 \\
0 \\
0\end{array}$ & $\begin{array}{l}8 \\
8 \\
\frac{1}{1} \\
\frac{1}{10} \\
0 \\
-1\end{array}$ & $\begin{array}{l}\frac{9}{1} \\
\frac{1}{1} \\
\frac{2}{2}\end{array}$ & 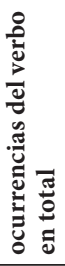 \\
\hline frutificar & 0 & 0 & 0 & 1 & 4 & 8 & 37 & 11 & 16 & 7 & 4 & 0 & 0 & 0 & 0 & 0 & 88 \\
\hline amplificar & 0 & 0 & 0 & 0 & 2 & 0 & 3 & 5 & 19 & 12 & 0 & 3 & 4 & 7 & 13 & 16 & 84 \\
\hline $\begin{array}{l}\text { vivificar / } \\
\text { uiuificar / } \\
\text { viuificar }\end{array}$ & 0 & 0 & 0 & 0 & 0 & 2 & 2 & 8 & 8 & 6 & 3 & 1 & 8 & 10 & 16 & 20 & 84 \\
\hline $\begin{array}{l}\text { dulcificar / } \\
\text { dulçificar }\end{array}$ & 0 & 0 & 0 & 0 & 0 & 2 & 0 & 0 & 0 & 0 & 0 & 3 & 2 & 19 & 31 & 21 & 78 \\
\hline magnificar & 0 & 1 & 4 & 0 & 6 & 16 & 5 & 7 & 11 & 1 & 3 & 0 & 0 & 0 & 3 & 7 & 64 \\
\hline unificar & 0 & 0 & 0 & 0 & 0 & 0 & 0 & 0 & 0 & 0 & 0 & 0 & 0 & 0 & 26 & 38 & 64 \\
\hline metrificar & 0 & 0 & 0 & 1 & 0 & 6 & 6 & 2 & 21 & 3 & 2 & 3 & 0 & 1 & 4 & 4 & 53 \\
\hline personificar & 0 & 0 & 0 & 0 & 0 & 0 & 0 & 0 & 1 & 0 & 0 & 0 & 1 & 4 & 21 & 24 & 51 \\
\hline intensificar & 0 & 0 & 0 & 0 & 0 & 0 & 0 & 0 & 0 & 0 & 0 & 0 & 0 & 0 & 0 & 48 & 48 \\
\hline damnificar & 0 & 0 & 0 & 0 & 1 & 0 & 5 & 8 & 17 & 8 & 2 & 0 & 2 & 1 & 1 & 0 & 45 \\
\hline retificar & 0 & 0 & 2 & 0 & 1 & 6 & 15 & 13 & 6 & 1 & 0 & 0 & 1 & 0 & 0 & 0 & 45 \\
\hline sanctificar & 0 & 0 & 1 & 0 & 1 & 0 & 3 & 8 & 16 & 6 & 0 & 0 & 0 & 0 & 0 & 0 & 35 \\
\hline dignificar & 0 & 0 & 0 & 0 & 0 & 1 & 0 & 1 & 0 & 0 & 0 & 0 & 1 & 0 & 8 & 23 & 34 \\
\hline dapnificar & 0 & 0 & 0 & 0 & 18 & 5 & 4 & 1 & 0 & 0 & 0 & 0 & 0 & 0 & 0 & 0 & 28 \\
\hline exemplificar & 0 & 0 & 0 & 0 & 0 & 3 & 4 & 5 & 9 & 3 & 1 & 0 & 0 & 0 & 0 & 0 & 25 \\
\hline beatificar & 0 & 0 & 0 & 0 & 0 & 2 & 2 & 4 & 3 & 5 & 1 & 0 & 1 & 1 & 3 & 2 & 24 \\
\hline deificar & 0 & 0 & 0 & 0 & 0 & 0 & 0 & 0 & 5 & 0 & 2 & 1 & 1 & 0 & 5 & 10 & 24 \\
\hline $\begin{array}{l}\text { diversificar / } \\
\text { diuersificar }\end{array}$ & 0 & 0 & 0 & 0 & 0 & 0 & 4 & 3 & 1 & 0 & 0 & 1 & 1 & 0 & 3 & 10 & 23 \\
\hline rrehedificar & 0 & 0 & 0 & 0 & 0 & 0 & 9 & 1 & 13 & 0 & 0 & 0 & 0 & 0 & 0 & 0 & 23 \\
\hline rehedificar & 0 & 0 & 0 & 0 & 3 & 0 & 7 & 2 & 10 & 0 & 0 & 0 & 0 & 0 & 0 & 0 & 22 \\
\hline sinifikar & 0 & 0 & 0 & 0 & 0 & 0 & 0 & 0 & 0 & 22 & 0 & 0 & 0 & 0 & 0 & 0 & 22 \\
\hline danificar & 0 & 0 & 0 & 1 & 0 & 0 & 4 & 7 & 6 & 1 & 0 & 0 & 0 & 0 & 0 & 0 & 19 \\
\hline dosificar & 0 & 0 & 0 & 0 & 0 & 0 & 0 & 0 & 0 & 0 & 0 & 0 & 0 & 0 & 0 & 19 & 19 \\
\hline mollificar & 0 & 0 & 0 & 0 & 0 & 3 & 13 & 2 & 1 & 0 & 0 & 0 & 0 & 0 & 0 & 0 & 19 \\
\hline molificar & 0 & 0 & 0 & 0 & 3 & 2 & 8 & 0 & 1 & 4 & 0 & 0 & 0 & 0 & 0 & 0 & 18 \\
\hline dampnificar & 0 & 0 & 0 & 0 & 12 & 2 & 1 & 0 & 0 & 0 & 0 & 0 & 0 & 0 & 0 & 0 & 15 \\
\hline rretificar & 0 & 0 & 0 & 0 & 0 & 4 & 10 & 0 & 0 & 0 & 0 & 0 & 0 & 0 & 0 & 0 & 14 \\
\hline cualificar & 0 & 0 & 0 & 0 & 0 & 0 & 0 & 0 & 10 & 2 & 0 & 0 & 0 & 0 & 0 & 1 & 13 \\
\hline petrificar & 0 & 0 & 0 & 0 & 0 & 0 & 0 & 0 & 0 & 0 & 0 & 4 & 0 & 3 & 1 & 4 & 12 \\
\hline redificar & 0 & 0 & 0 & 0 & 0 & 2 & 1 & 3 & 1 & 2 & 0 & 2 & 1 & 0 & 0 & 0 & 12 \\
\hline solidificar & 0 & 0 & 0 & 0 & 0 & 0 & 0 & 0 & 0 & 0 & 0 & 0 & 0 & 0 & 9 & 3 & 12 \\
\hline enxenplificar & 0 & 0 & 0 & 0 & 0 & 7 & 3 & 1 & 0 & 0 & 0 & 0 & 0 & 0 & 0 & 0 & 11 \\
\hline plantificar & 0 & 0 & 0 & 0 & 0 & 0 & 0 & 0 & 0 & 0 & 0 & 7 & 4 & 0 & 0 & 0 & 11 \\
\hline exenplificar & 0 & 0 & 0 & 0 & 0 & 9 & 0 & 0 & 0 & 1 & 0 & 0 & 0 & 0 & 0 & 0 & 10 \\
\hline bonificar & 0 & 0 & 0 & 0 & 0 & 0 & 3 & 1 & 1 & 0 & 0 & 0 & 0 & 0 & 2 & 2 & 9 \\
\hline $\begin{array}{l}\text { expecificar / } \\
\text { expeçificar }\end{array}$ & 0 & 0 & 0 & 0 & 0 & 3 & 0 & 1 & 1 & 1 & 0 & 2 & 1 & 0 & 0 & 0 & 9 \\
\hline
\end{tabular}




\begin{tabular}{|c|c|c|c|c|c|c|c|c|c|c|c|c|c|c|c|c|c|}
\hline : & 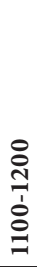 & 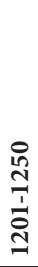 & $\begin{array}{l}\stackrel{8}{0} \\
\stackrel{-}{7} \\
\stackrel{1}{1} \\
\stackrel{1}{1}\end{array}$ & 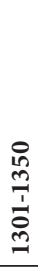 & 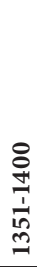 & 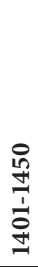 & 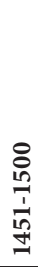 & $\begin{array}{l}0 \\
10 \\
10 \\
1 \\
1 \\
0 \\
10\end{array}$ & $\begin{array}{l}8 \\
0 \\
\frac{0}{1} \\
1 \\
10 \\
\end{array}$ & $\begin{array}{l}0 \\
10 \\
1 \\
1 \\
0 \\
0 \\
-1\end{array}$ & $\begin{array}{l}8 \\
\frac{8}{1} \\
\frac{1}{10} \\
0 \\
-1\end{array}$ & 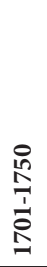 & $\begin{array}{l}8 \\
0 \\
\frac{\infty}{1} \\
\frac{1}{1}\end{array}$ & 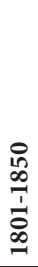 & $\begin{array}{l}8 \\
\stackrel{0}{2} \\
\frac{1}{10} \\
\infty \\
-1\end{array}$ & $\frac{8}{10}$ & 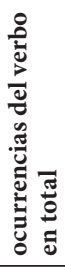 \\
\hline pontificar & 0 & 0 & 0 & 0 & 0 & 0 & 0 & 0 & 1 & 3 & 0 & 0 & 1 & 0 & 0 & 4 & 9 \\
\hline escarificar & 0 & 0 & 0 & 0 & 0 & 0 & 0 & 1 & 4 & 1 & 0 & 1 & 0 & 0 & 0 & 1 & 8 \\
\hline rarificar & 0 & 0 & 0 & 0 & 0 & 0 & 0 & 0 & 5 & 0 & 0 & 0 & 1 & 0 & 2 & 0 & 8 \\
\hline descalificar & 0 & 0 & 0 & 0 & 0 & 0 & 0 & 0 & 0 & 0 & 0 & 0 & 0 & 0 & 0 & 7 & 7 \\
\hline anplificar & 0 & 0 & 0 & 0 & 0 & 0 & 0 & 0 & 1 & 5 & 0 & 0 & 0 & 0 & 0 & 0 & 6 \\
\hline cuantificar & 0 & 0 & 0 & 0 & 0 & 0 & 0 & 0 & 0 & 0 & 0 & 0 & 0 & 0 & 0 & 6 & 6 \\
\hline dannificar & 0 & 0 & 0 & 0 & 0 & 0 & 1 & 4 & 0 & 1 & 0 & 0 & 0 & 0 & 0 & 0 & 6 \\
\hline iustificar & 0 & 0 & 0 & 0 & 2 & 0 & 3 & 0 & 1 & 0 & 0 & 0 & 0 & 0 & 0 & 0 & 6 \\
\hline planificar & 0 & 0 & 0 & 0 & 0 & 0 & 0 & 0 & 0 & 0 & 0 & 4 & 1 & 0 & 0 & 1 & 6 \\
\hline specificar & 0 & 0 & 0 & 2 & 0 & 0 & 1 & 0 & 3 & 0 & 0 & 0 & 0 & 0 & 0 & 0 & 6 \\
\hline vitrificar & 0 & 0 & 0 & 0 & 0 & 0 & 0 & 0 & 0 & 0 & 0 & 0 & 0 & 0 & 4 & 2 & 6 \\
\hline asacrificar & 0 & 0 & 0 & 0 & 5 & 0 & 0 & 0 & 0 & 0 & 0 & 0 & 0 & 0 & 0 & 0 & 5 \\
\hline nidificar & 0 & 0 & 0 & 0 & 0 & 0 & 0 & 0 & 5 & 0 & 0 & 0 & 0 & 0 & 0 & 0 & 5 \\
\hline onorificar & 0 & 0 & 0 & 0 & 0 & 0 & 5 & 0 & 0 & 0 & 0 & 0 & 0 & 0 & 0 & 0 & 5 \\
\hline revivificar & 0 & 0 & 0 & 0 & 0 & 0 & 0 & 0 & 0 & 2 & 0 & 0 & 0 & 0 & 2 & 1 & 5 \\
\hline codificar & 0 & 0 & 0 & 0 & 0 & 0 & 0 & 0 & 0 & 0 & 0 & 0 & 0 & 1 & 2 & 1 & 4 \\
\hline manificar & 0 & 0 & 0 & 0 & 0 & 2 & 0 & 2 & 0 & 0 & 0 & 0 & 0 & 0 & 0 & 0 & 4 \\
\hline rubificar & 0 & 0 & 0 & 0 & 0 & 0 & 0 & 0 & 0 & 0 & 0 & 4 & 0 & 0 & 0 & 0 & 4 \\
\hline virificar & 0 & 0 & 0 & 0 & 0 & 3 & 0 & 1 & 0 & 0 & 0 & 0 & 0 & 0 & 0 & 0 & 4 \\
\hline abtificar & 0 & 0 & 0 & 0 & 0 & 3 & 0 & 0 & 0 & 0 & 0 & 0 & 0 & 0 & 0 & 0 & 3 \\
\hline biuificar & 0 & 0 & 0 & 0 & 1 & 0 & 2 & 0 & 0 & 0 & 0 & 0 & 0 & 0 & 0 & 0 & 3 \\
\hline cantificar & 0 & 0 & 0 & 0 & 0 & 3 & 0 & 0 & 0 & 0 & 0 & 0 & 0 & 0 & 0 & 0 & 3 \\
\hline expaçificar & 0 & 0 & 0 & 0 & 0 & 3 & 0 & 0 & 0 & 0 & 0 & 0 & 0 & 0 & 0 & 0 & 3 \\
\hline henificar & 0 & 0 & 0 & 0 & 0 & 0 & 0 & 0 & 0 & 0 & 0 & 0 & 0 & 0 & 0 & 3 & 3 \\
\hline honorificar & 0 & 0 & 0 & 1 & 1 & 0 & 0 & 0 & 0 & 0 & 0 & 0 & 1 & 0 & 0 & 0 & 3 \\
\hline mistificar & 0 & 0 & 0 & 0 & 0 & 0 & 0 & 0 & 0 & 0 & 0 & 0 & 0 & 0 & 1 & 2 & 3 \\
\hline panificar & 0 & 0 & 0 & 0 & 0 & 0 & 1 & 0 & 2 & 0 & 0 & 0 & 0 & 0 & 0 & 0 & 3 \\
\hline pasçificar & 0 & 0 & 0 & 0 & 2 & 0 & 1 & 0 & 0 & 0 & 0 & 0 & 0 & 0 & 0 & 0 & 3 \\
\hline sygnificar & 0 & 0 & 0 & 0 & 0 & 0 & 3 & 0 & 0 & 0 & 0 & 0 & 0 & 0 & 0 & 0 & 3 \\
\hline amortificar & 0 & 0 & 0 & 0 & 0 & 1 & 1 & 0 & 0 & 0 & 0 & 0 & 0 & 0 & 0 & 0 & 2 \\
\hline $\begin{array}{l}\text { apacificar / } \\
\text { apaçificar }\end{array}$ & 0 & 0 & 0 & 1 & 0 & 0 & 1 & 0 & 0 & 0 & 0 & 0 & 0 & 0 & 0 & 0 & 2 \\
\hline dagnificar & 0 & 0 & 0 & 0 & 0 & 1 & 0 & 1 & 0 & 0 & 0 & 0 & 0 & 0 & 0 & 0 & 2 \\
\hline edifikar & 0 & 0 & 0 & 0 & 0 & 0 & 0 & 0 & 0 & 2 & 0 & 0 & 0 & 0 & 0 & 0 & 2 \\
\hline esclarificar & 0 & 0 & 0 & 0 & 0 & 0 & 1 & 1 & 0 & 0 & 0 & 0 & 0 & 0 & 0 & 0 & 2 \\
\hline espiçificar & 0 & 0 & 0 & 0 & 0 & 2 & 0 & 0 & 0 & 0 & 0 & 0 & 0 & 0 & 0 & 0 & 2 \\
\hline lapidificar & 0 & 0 & 0 & 0 & 0 & 2 & 0 & 0 & 0 & 0 & 0 & 0 & 0 & 0 & 0 & 0 & 2 \\
\hline minorificar & 0 & 0 & 0 & 0 & 0 & 2 & 0 & 0 & 0 & 0 & 0 & 0 & 0 & 0 & 0 & 0 & 2 \\
\hline momificar & 0 & 0 & 0 & 0 & 0 & 0 & 0 & 0 & 0 & 0 & 0 & 0 & 0 & 0 & 2 & 0 & 2 \\
\hline pedrificar & 0 & 0 & 0 & 0 & 0 & 2 & 0 & 0 & 0 & 0 & 0 & 0 & 0 & 0 & 0 & 0 & 2 \\
\hline
\end{tabular}




\begin{tabular}{|c|c|c|c|c|c|c|c|c|c|c|c|c|c|c|c|c|c|}
\hline 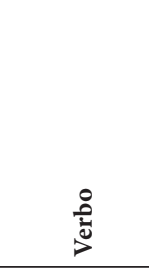 & 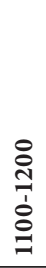 & 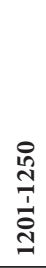 & $\begin{array}{l}8 \\
\stackrel{0}{n} \\
\stackrel{1}{1} \\
\stackrel{1}{1}\end{array}$ & $\begin{array}{l}8 \\
0 \\
\stackrel{1}{1} \\
\stackrel{1}{1} \\
\stackrel{0}{n}\end{array}$ & $\begin{array}{l}8 \\
0 \\
1 \\
1 \\
1 \\
0\end{array}$ & 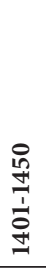 & $\begin{array}{l}8 \\
8 \\
11 \\
11 \\
11\end{array}$ & $\begin{array}{l}8 \\
10 \\
10 \\
11 \\
0 \\
10\end{array}$ & $\begin{array}{l}8 \\
8 \\
0 \\
1 \\
10 \\
10\end{array}$ & $\begin{array}{l}8 \\
0 \\
0 \\
1 \\
0 \\
0 \\
-1\end{array}$ & $\begin{array}{l}8 \\
\frac{1}{1} \\
1 \\
0 \\
0\end{array}$ & 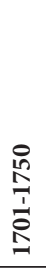 & $\begin{array}{l}8 \\
0 \\
0 \\
1 \\
1 \\
1\end{array}$ & $\begin{array}{l}8 \\
\infty \\
\infty \\
1 \\
0 \\
0 \\
-1\end{array}$ & $\begin{array}{l}8 \\
\stackrel{0}{1} \\
\frac{1}{10} \\
\infty\end{array}$ & 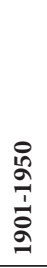 & 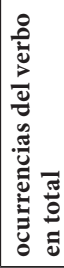 \\
\hline reidificar & 0 & 0 & 0 & 0 & 0 & 2 & 0 & 0 & 0 & 0 & 0 & 0 & 0 & 0 & 0 & 0 & 2 \\
\hline acidificar & 0 & 0 & 0 & 0 & 0 & 0 & 0 & 0 & 0 & 0 & 0 & 0 & 0 & 0 & 0 & 1 & 1 \\
\hline agratificar & 0 & 0 & 0 & 0 & 0 & 0 & 1 & 0 & 0 & 0 & 0 & 0 & 0 & 0 & 0 & 0 & 1 \\
\hline amolificar & 0 & 0 & 0 & 0 & 0 & 1 & 0 & 0 & 0 & 0 & 0 & 0 & 0 & 0 & 0 & 0 & 1 \\
\hline kruzifikar & 0 & 0 & 0 & 0 & 0 & 0 & 0 & 0 & 0 & 1 & 0 & 0 & 0 & 0 & 0 & 0 & 1 \\
\hline dañificar & 0 & 0 & 0 & 0 & 0 & 0 & 1 & 0 & 0 & 0 & 0 & 0 & 0 & 0 & 0 & 0 & 1 \\
\hline dapñificar & 0 & 0 & 0 & 0 & 0 & 0 & 1 & 0 & 0 & 0 & 0 & 0 & 0 & 0 & 0 & 0 & 1 \\
\hline desedificar & 0 & 0 & 0 & 0 & 0 & 0 & 0 & 0 & 0 & 1 & 0 & 0 & 0 & 0 & 0 & 0 & 1 \\
\hline desmitificar & 0 & 0 & 0 & 0 & 0 & 0 & 0 & 0 & 0 & 0 & 0 & 0 & 0 & 0 & 0 & 1 & 1 \\
\hline escarnificar & 0 & 0 & 0 & 0 & 0 & 0 & 1 & 0 & 0 & 0 & 0 & 0 & 0 & 0 & 0 & 0 & 1 \\
\hline escenificar & 0 & 0 & 0 & 0 & 0 & 0 & 0 & 0 & 0 & 0 & 0 & 0 & 0 & 0 & 0 & 1 & 1 \\
\hline esdificar & 0 & 0 & 0 & 0 & 0 & 0 & 1 & 0 & 0 & 0 & 0 & 0 & 0 & 0 & 0 & 0 & 1 \\
\hline estratificar & 0 & 0 & 0 & 0 & 0 & 0 & 0 & 0 & 0 & 0 & 0 & 0 & 0 & 0 & 0 & 1 & 1 \\
\hline estrellificar & 0 & 0 & 0 & 0 & 0 & 1 & 0 & 0 & 0 & 0 & 0 & 0 & 0 & 0 & 0 & 0 & 1 \\
\hline falsifikar & 0 & 0 & 0 & 0 & 0 & 0 & 0 & 0 & 0 & 1 & 0 & 0 & 0 & 0 & 0 & 0 & 1 \\
\hline frantificar & 0 & 0 & 0 & 0 & 0 & 1 & 0 & 0 & 0 & 0 & 0 & 0 & 0 & 0 & 0 & 0 & 1 \\
\hline gasificar & 0 & 0 & 0 & 0 & 0 & 0 & 0 & 0 & 0 & 0 & 0 & 0 & 0 & 0 & 0 & 1 & 1 \\
\hline mortifikar & 0 & 0 & 0 & 0 & 0 & 0 & 0 & 0 & 0 & 1 & 0 & 0 & 0 & 0 & 0 & 0 & 1 \\
\hline munidificar & 0 & 0 & 0 & 0 & 0 & 0 & 0 & 1 & 0 & 0 & 0 & 0 & 0 & 0 & 0 & 0 & 1 \\
\hline odorificar & 0 & 0 & 0 & 0 & 0 & 0 & 1 & 0 & 0 & 0 & 0 & 0 & 0 & 0 & 0 & 0 & 1 \\
\hline ramificar & 0 & 0 & 0 & 0 & 0 & 0 & 0 & 0 & 0 & 0 & 0 & 0 & 0 & 0 & 0 & 1 & 1 \\
\hline restificar & 0 & 0 & 0 & 0 & 0 & 0 & 1 & 0 & 0 & 0 & 0 & 0 & 0 & 0 & 0 & 0 & 1 \\
\hline siginificar & 0 & 0 & 0 & 0 & 0 & 0 & 1 & 0 & 0 & 0 & 0 & 0 & 0 & 0 & 0 & 0 & 1 \\
\hline synificar & 0 & 0 & 0 & 0 & 0 & 1 & 0 & 0 & 0 & 0 & 0 & 0 & 0 & 0 & 0 & 0 & 1 \\
\hline tubificar & 0 & 0 & 0 & 0 & 0 & 0 & 0 & 0 & 0 & 0 & 0 & 1 & 0 & 0 & 0 & 0 & 1 \\
\hline 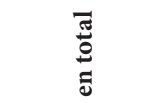 & $a$ & $\simeq$ & लn & के & ส & กิ & $\underset{I}{ \pm}$ & $\stackrel{\infty}{\stackrel{\infty}{-}}$ & 命 & 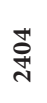 & $\hat{\widehat{ก}}$ & $\tilde{\widehat{6}}$ & $\stackrel{N}{N}$ & $\overline{\mathrm{I}}$ & 荗 & 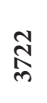 & $\begin{array}{l}\text { ڤे } \\
\stackrel{\text { సे }}{0}\end{array}$ \\
\hline
\end{tabular}




\section{Conclusiones y discusión}

De la parte cualitativa de nuestro análisis resulta que las bases de los verbos terminados en -ificar son de carácter nominal y adjetival (aunque es difícil determinar cuál de los dos es más común en los periodos reportados). En cuanto a las alternaciones fonéticas y ortográficas, generalmente han prevalecido las formas que se acercan más a las originales, o sea latinas.

Vale la pena mencionar algunos aspectos más. Ante todo, la vasta mayoría de las bases que aparecen con el sufijo -ificar prefiere la forma latina a la española (aunque ocasionalmente las formas latinas y españolas son idénticas). Solo en muy pocos casos el origen español es indudable (p. ej. henificar). Este hecho sugiere que, en la mayoría de casos, se trata de préstamos tomados o bien directamente del latín, o bien de alguna otra lengua europea que en dicha época fue portadora de avance cultural, técnico o científico (italiano, francés, inglés). Con relación al origen de los préstamos en -ificar sería interesante llevar a cabo un estudio comparativo entre varios idiomas, tanto europeos (italiano, francés, inglés), cuanto iberorrománicos (catalán, portugués, etc.).

Por otra parte, hay que tener en cuenta que la primera ocurrencia de un verbo en un corpus diacrónico como el CORDE - por muy extenso y representativo que sea- en una época determinada no significa necesariamente al mismo tiempo su primera apariencia en la lengua española. A este respecto tal vez pueda ser oportuno comparar los resultados que trae el CORDE con los de otro corpus diacrónico: se ofrece aquí, sobre todo, el Corpus del Español $\left.{ }^{34}\right)$.

En cuanto a nuestro análisis cuantitativo cabe destacar algunos momentos. El crecimiento sustancial que se inicia en el periodo de 1351-1400 y alcanza su máximo en 1451-1500 posiblemente puede reflejar el flujo de los préstamos del latín -y, tal vez, del italiano (cf. Dworkin, 2004: 652)- que es característico a partir de la segunda mitad del s. XIV y continúa durante todo el s. XV, como apuntan Dworkin (2004: 649) y Cano Aguilar (1997: 218) ${ }^{35}$. Como ya hemos advertido, otro cambio considerable se nota en la primera mitad del siglo XVI. En esta época aparece, como constatan Cano Aguilar (1997: 251) y Verdonk (2004: 908-909), una bajada general en la presencia de latinismos en español, con la cual tal vez podría relacionarse también la caída de la ocurrencia de los verbos acabados en el sufijo -ificar. Otra caída interesante se advierte en la primera mitad del siglo XX. Esta parece ser contradictoria a las afirmaciones generales que se dan sobre el crecimiento de tecnicismos durante los últimos siglos. No hay que olvidar, sin embargo, que nuestro análisis cuantitativo ha tratado solo con la frecuencia de tokens (a pesar de la disminución de tokens sí que se documentan nuevos verbos en esta época, como resulta de la parte cualitativa de nuestro análisis). Es posible, por ejemplo, que algunos verbos causativos en -ificar hayan perdido su frecuencia de uso en favor de sus homólogos creados mediante otros sufijos más comunes, p. ej. amplificar (que alcanza su pico en el s. XVI en nuestro análisis) frente al mucho más común ampliar, clarificar (con bastantes ocurrencias en el s. XV) frente a aclarar, etc.

34 Este corpus (en línea accesible en: http://www.corpusdelespanol.org) cuenta actualmente con unos 100 millones de palabras (tokens) y cubre el periodo del siglo XIII al siglo XX, cf. Davies (2002 a, b).

35 Bustos Tovar (1977) advierte que muchos latinismos que aparecen esporádicamente en la primera mitad del siglo XIII reaparecen en la lengua en el siglo XV. 


\section{BIBLIOGRAFÍA}

Alvar, M. - Mariner, S. (1967): Latinismos. In: Alvar, M., et al. (eds.), Enciclopedia Lingüística Hispánica, Volume II: Elementos constitutivos. Fuentes. Madrid: CSIC, pp. 3-49.

Bauer, L. (2001): Morphological Productivity. Cambridge: Cambridge University Press.

Bustos Tovar, J. J. de (1977): Nota sobre el cultismo léxico en la literatura medieval española. In: XIV Congresso Internazionale di Linguistica e Filologia Romanza, IV, Napoli, 233-250.

Cano Aguilar, R. (1997): El español a través de los tiempos. Madrid: Arco Libros.

Cano Aguilar, R. (ed.) (2004): Historia de la lengua española. Barcelona: Ariel.

Davies, M. (2002a): Corpus del Español: 100 million words, 1200s-1900s. [en línea]. http://www .corpusdelespanol.org

Davies, M. (2002b): Un corpus anotado de 100.000 .000 palabras del español histórico y moderno. Procesamiento del lenguaje natural, núm. 29, pp. 21-27.

Dunning, T. (1993): Accurate Methods for the Statistics of Surprise and Coincidence. Computational Linguistics, vol. 19, 1, pp. 61-74.

Dworkin, S. N. (2004): La transición léxica en el español bajomedieval. In: Cano (ed.), Historia de la lengua española. Barcelona: Ariel.

Gómez de Silva, G. (1998): Breve diccionario etimológico de la lengua española. México: Fondo de Cultura Económica.

Lavale Ortiz, R. M. (2007): Causatividad y verbos denominales. ELUA. Estudios de Lingüística, núm. 21, pp. 171-207.

Pharies, D. (2004): Tipología de los orígenes de los sufijos españoles. Revista de Filología Española, LXXXIV, 1, pp. 153-167.

Penny, R. (2001): Gramática histórica del español. Barcelona: Ariel.

Real Academia Española: Banco de datos (CORDE) [en línea]. Corpus diacrónico del español <http:// www.rae.es>

Real Academia Española: Diccionario de la RAE (DRAE). [en línea]. <http://www.rae.es>

Rifón, A. (1997): Pautas semánticas para la formación de verbos en español mediante sufijación. Santiago de Compostela: Universidad de Santiago de Compostela.

Verdonk, R. (2004): Cambios en el léxico del español durante la época de los Austrias. In: Cano Aguilar, R. (ed.): Historia de la lengua española. Barcelona: Ariel, pp. 895-916.

\section{Zuzana Krinková}

Instituto de Estudios Románicos, Facultad de Filosofía y Letras, Universidad Carolina

nám. Jana Palacha 2, 11638 Praha 1

zuzana.krinkova@ff.cuni.cz 